\title{
Correlation between TEM, SAXS and DSC to investigate the influence of SPD on precipitation mechanisms of an AI-Zn- $\mathrm{Mg}-\mathrm{Cu}$ alloy
}

\author{
Amandine Duchaussoy ${ }^{1, *}$, Alexis Deschamps ${ }^{2}$, Xavier Sauvage ${ }^{1}$, Frédéric De Geuser $^{2},{\text { Zenji } \text { Horita }^{3}}^{3}$ \\ ${ }^{1}$ Normandie Univ, UNIROUEN, INSA Rouen, CNRS, Groupe de Physique des Matériaux, 76000, Rouen, France \\ ${ }^{2}$ Univ. Grenoble Alpes, CNRS, Grenoble INP, SIMaP, F-38000, Grenoble, France \\ ${ }^{3}$ School of Engineering, Kyushu Institute of Technology, Kitakyushu, 804-8550, Japan
}

\begin{abstract}
This study allowed to understand the influence of severe plastic deformation by High Pressure Torsion (HPT) on an Al-Zn-Mg-Cu alloy and more especially the influence on precipitation mechanisms thanks to the correlation between DSC, SAXS and STEM data. A shear strain of $\gamma \approx 200$ was first applied to the alloy. This deformation leads to nanostructuration, creation of high density of defects but also solute segregation to boundaries and dynamic precipitation. These specific microstructural features give rise to an acceleration of precipitation kinetics during heat treatments but also to a lower precipitation temperature and a modification of final precipitates size distribution as compared to the un-deformed alloy.
\end{abstract}

\section{Introduction}

7\#\#\# aluminium alloys are high strength alloys mainly used for aerospace applications due to their high specific mechanical properties [1]. However, in order to further increase these properties, we propose to combine precipitation hardening with grain boundary strengthening thanks to ultrafine-grained (UFG) structures. It has been shown that severe plastic deformation (SPD) achieved for example by equalchannel angular pressing (ECAP) or high-pressure torsion (HPT) may efficiently refine coarse-grained microstructures down to the sub-micrometer scale in a large variety of aluminum alloys [2-5]. However, the extreme level of strain applied during these processes leads to a very high level of stored energy that usually gives a poor microstructure thermal stability and a faster precipitation kinetics [6,7]. This is attributed to an increased atomic mobility promoted by crystalline defects and to a lowering of the nucleation barrier.

In this study, results obtained by small angle X-Ray scattering (SAXS), differential scanning calorimetry (DSC) and transmission electron microscopy have been correlated to understand the deformation influence on the precipitation of an $\mathrm{Al}-\mathrm{Zn}-\mathrm{Mg}-\mathrm{Cu}$ alloy.

\section{Experimental}

\subsection{Material}

The material investigated in the present study has the following composition (wt.\%) of: Al 87.19\%, $\mathrm{Zn}$ $9.46 \%, \mathrm{Mg} 1.87 \%, \mathrm{Cu} 1.33 \%$, Fe $0.8 \%$ and $\%<0.2 \mathrm{Zr}+\mathrm{Sc}$. This alloy has been cast with an ultra-fast solidification rate to promote a fine initial intermetallics distribution. It was subsequently solution heat treated at $474^{\circ} \mathrm{C}$ during $1 \mathrm{~h}$.

\subsection{High Pressure Torsion (HPT)}

The HPT process (Fig. 1) has been used to deform the alloy. Disc shape sample of $10 \mathrm{~mm}$ diameter and $1 \mathrm{~mm}$ thickness was deformed under a pressure of $6 \mathrm{GPa}$ at RT with a rotation speed of $1 \mathrm{rpm}$. The shear deformation is a function of the number of revolutions $N$, the distance from the disc centre $r$ and its thickness after HPT $h$ [8]:

$$
\gamma=\frac{2 \pi N \cdot r}{h}
$$




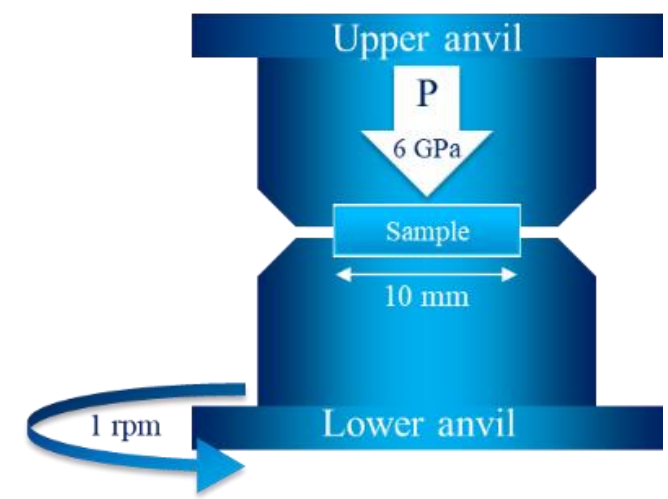

Fig. 1 : Schematic representation of HPT process

In this study, the level of deformation has been achieved by applying 10 revolutions. The anvil temperature, monitored during processing with an infrared temperature measurement device, never exceeded $50{ }^{\circ} \mathrm{C}$.

\subsection{Characterization methods}

Microstructure and more specifically precipitates evolution were observed using several complementary techniques.

First, scanning electron microscopy (SEM) was performed with a Gemini Leo1530 FEG-SEM microscope using back-scattered electron (BSE) detector.

Scanning Transmission Electron Microscopy (STEM) was carried out using a JEOL ARM-200F operated at $200 \mathrm{kV}$. Dark Field (DF - collection angles 20-80 mrad) and high-angle annular dark field (HAADF - collection angles 80-180 mrad) images were recorded with a probe size of $0.2 \mathrm{~nm}$ and a convergence angle of $34 \mathrm{mrad}$. TEM samples were prepared as $3 \mathrm{~mm}$ diameter discs whose center was halfway between the center and the edge of the HPT disc. At this location, the corresponding shear strain can be estimated thanks to eq.(1) to $\gamma \approx 200$. Then TEM foils were prepared by conventional mechanical polishing down to $100 \mu \mathrm{m}$ thickness, followed by double-jet electropolishing (performed on a Stuers TenuPol-5) with a mixture of $30 \%$ $\mathrm{HNO} 3+70 \% \mathrm{CH} 3 \mathrm{OH}$ at a temperature of $-30{ }^{\circ} \mathrm{C}(\sim 20$ $\mathrm{V})$.

Differential Scanning Calorimetry (DSC) measurements were performed using a Mettler Toledo DSC $3+$ at a heating rate of $20{ }^{\circ} \mathrm{C} / \mathrm{min}$ up to $500{ }^{\circ} \mathrm{C}$. Samples were placed in pure $\mathrm{Al}$ crucibles with a capacity of 401 able to receive samples with an average size of $3 * 3 \mathrm{~mm}$ and a weight between 30 and $50 \mathrm{mg}$.

$\mathrm{X}$-ray diffraction (XRD) analysis was carried out with diffractometer operating with $\mathrm{CuK} \alpha$ irradiation with an accelerating voltage of $40 \mathrm{kV}$ and a current of $40 \mathrm{~mA}$. The $\mathrm{K} \alpha 2$ radiation was filtered out from the XRD profile.

SAXS was performed on a custom built laboratory setup with a rotating anode source at the $\mathrm{K} \alpha$ energy of $\mathrm{Cu}$ (about $8 \mathrm{keV}$ ) and a Pilatus 2D detector. CCD camera data were corrected for read-out noise, distortion, flat-field and background noise. In situ experiments were carried out using a dedicated furnace in which the samples, thinned to $70-100 \mu \mathrm{m}$, were placed. The diameter of the X-ray beam was $1 \mathrm{~mm}$, and the signal was recorded from a location placed at the mid-distance between the center and the edge of the HPT-processed disc in order to probe a reproducible microstructure from one sample to the other and to be able to correlate this data with STEM observations. The SAXS 2D-data was radially averaged and normalized into the 1D-profile of scattered intensity I versus the scattering vector amplitude q; detailed procedures for data interpretation and used model can be found in [9-11]. This model needs some hypothesis which can be given by other experimental methods like

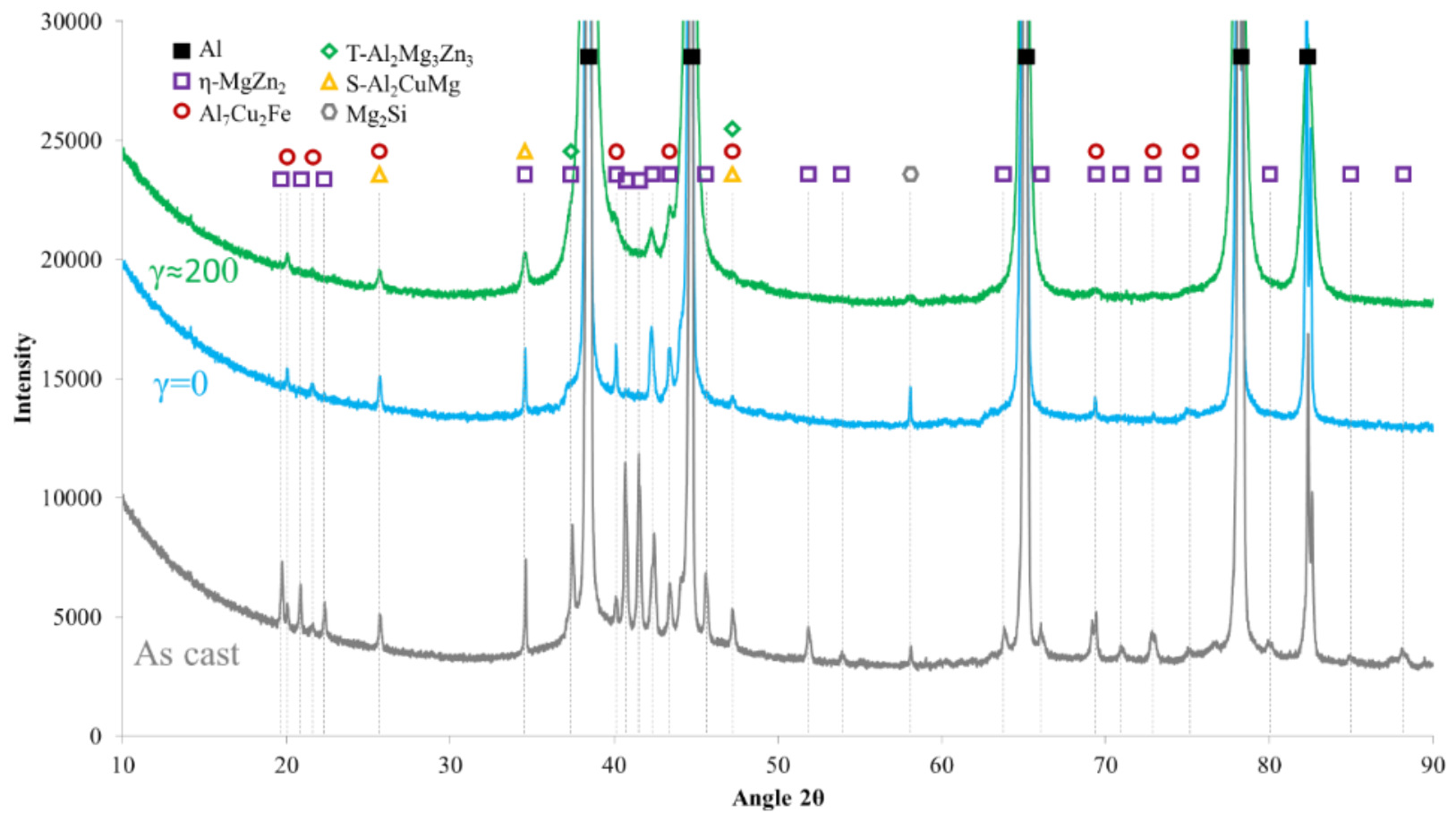

Fig. 2 : XRD patterns of an Al-Zn-Mg-Cu alloy after casting, after solution treatment $(\gamma=0)$ and after deformation by HPT $(\gamma \approx 200)$. 
precipitates composition in $\mathrm{Zn}$ (around 53\%) and their shape (assumed to be spherical).

\section{Results}

\subsection{Influence of deformation on microstructure}

\subsubsection{Influence on present phases}

First, XRD analyses (Fig. 2) show the presence of different phases after casting such as $\eta, T, S$ which are mainly composed of $\mathrm{Zn}, \mathrm{Mg}$ and $\mathrm{Cu}$. But also the presence of $\mathrm{Al}_{7} \mathrm{Cu}_{2} \mathrm{Fe}$ intermetallic phase. After solution treatment at $474{ }^{\circ} \mathrm{C}$ during $1 \mathrm{~h}$, most of the $\eta$ peaks disappear which means a large dissolution of this phase. Some enriched $\mathrm{Zn}-\mathrm{Mg}-\mathrm{Cu}$ remain after solution treatment but with a small amount. And insoluble $\mathrm{Al}_{7} \mathrm{Cu}_{2} \mathrm{Fe}$ intermetallic particles are still present. After HPT deformation, all peaks are still exhibited and no other appears, which means that dissolution or precipitation of a new phase induced by deformation probably did not occur.

As expected, the aluminium peaks of the deformed ultra-fine grain material are broader than the ones of the un-deformed coarse grain material. This broadening is due to the increase of defects introduced during the HPT intense deformation, namely grain boundaries, sub-grain boundaries and dislocations [12]. The diminution of some peaks intensity could the results of fragmentation of particles down to the nanoscale.

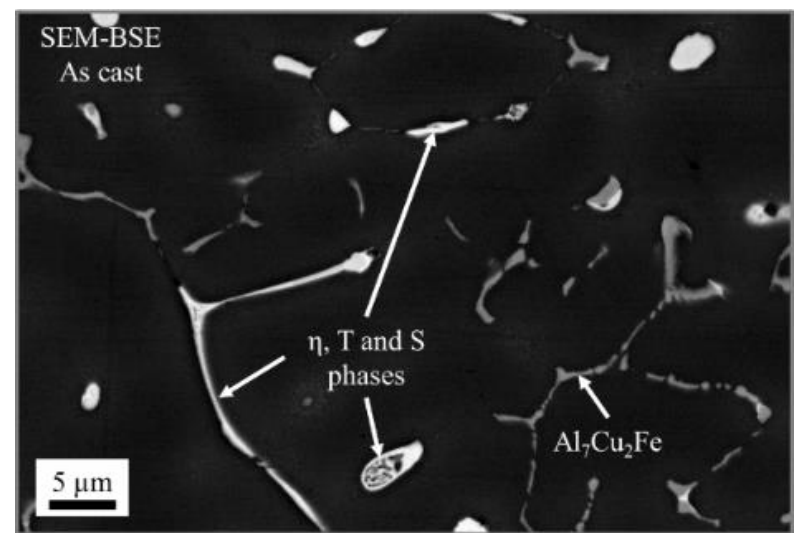

Fig. 3 : SEM-BSE image of as cast Al-Zn-Mg-Cu alloy

SEM-BSE images of as cast alloy (Fig. 3) confirm the presence of the different phases revealed by the XRD pattern. Image on Fig. 4(a), after solution treatment shows the un-dissolved intermetallic particles. SEM-BSE images after deformation (Fig. 4(b)) shows only a limited fragmentation of these intermetallic particles. Quantitative measurements reveal that the average intermetallic particles size evolved from $0.76 \pm 0.01 \mathrm{~m}$ to $0.55 \pm 0.02 \mathrm{~m}$. And that the surface fraction is stable.
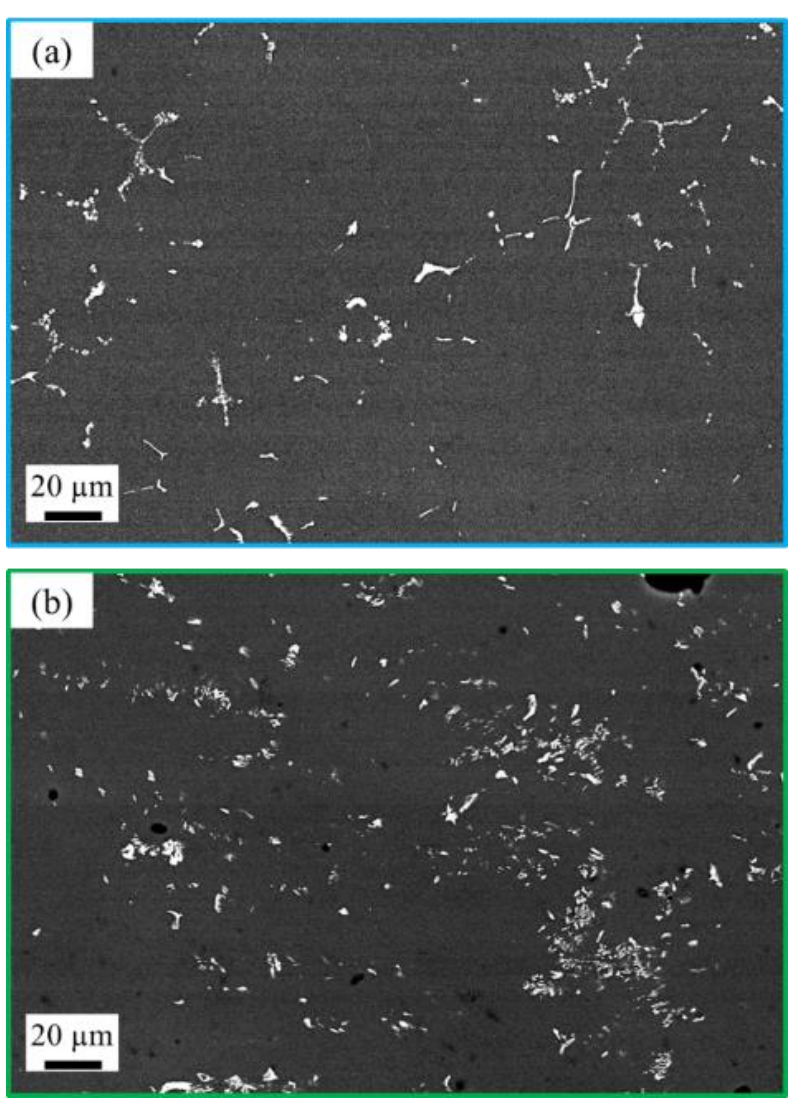

Fig. 4 : SEM-BSE images of Al-Zn-Mg-Cu alloy after solution treatment (a) and after deformation by HPT (b)

\subsubsection{Nanostructure formation by intense deformation}

The STEM-HAADF images of Fig. 5(a) and (b) recorded in the un-deformed material (after quenching from solution treatment and natural ageing) shows a subgrain boundary on which some heterogeneous precipitation occurred. A higher magnification image (Fig. 5(c)) allows to visualize $\mathrm{Al}_{3}(\mathrm{Sc}, \mathrm{Zr}$ ) dispersoïds and to distinguish some very small precipitates which can be identified as GP-zones thanks to previous works [13-15].

After deformation (Fig. 5(d,e,f)) the microstructure is significantly different. The DF image (Fig. 5(d)) exhibits lots of disorientations, which can be grain or subgrain boundaries or even dislocations. The HAADF $\mathrm{Z}$ contrast images (Fig. 5(e,f)) highlight segregation of heavy elements on these defects but also locally precipitation. EDS measurements (shown in Table 1) reveal that segregations and precipitations are enriched in $\mathrm{Zn}, \mathrm{Mg}$ and $\mathrm{Cu}$. 

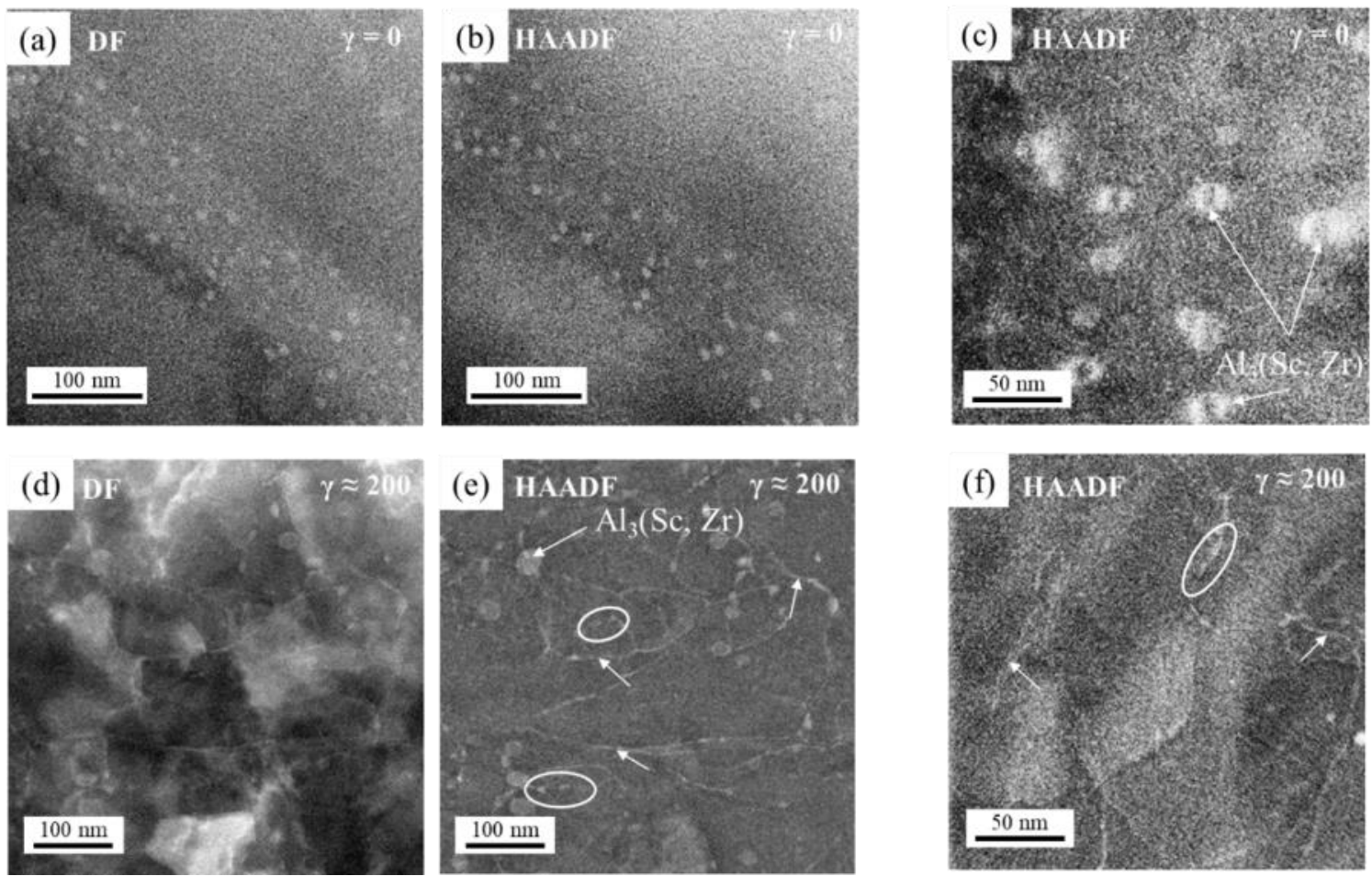

Fig. 5 : Dark field (a,d) and HAADF (b, c, e, f) images of un-deformed sample (a,b,c) and HPT deformed sample (d, e, f) of an $\mathrm{Al}-\mathrm{Zn}-\mathrm{Mg}-\mathrm{Cu}$ alloy.

\begin{tabular}{c|cc|cc}
\hline \multirow{2}{*}{ wt.\% } & Matrix & $\sigma$ & Precipitates & $\sigma$ \\
\cline { 2 - 5 } $\mathrm{Al}$ & 71.4 & 0.5 & 61.8 & 0.5 \\
\cline { 2 - 5 } $\mathrm{Zn}$ & 21.3 & 0.4 & 28.9 & 0.4 \\
$\mathrm{Mg}$ & 1.8 & 0.2 & 2.6 & 0.2 \\
$\mathrm{Cu}$ & 5.0 & 0.2 & 6.2 & 0.3 \\
$\mathrm{Sc}$ & 0.0 & 0.0 & 0.0 & 0.0 \\
$\mathrm{Zr}$ & 0.2 & 0.3 & 0.1 & 0.3 \\
$\mathrm{Fe}$ & 0.4 & 0.1 & 0.4 & 0.1 \\
\hline
\end{tabular}

Table. 1 : EDS measurements in the matrix and in precipitates (heterogeneous precipitation) for the un-deformed sample.

These results show that HPT deformation has a huge influence on the microstructure, and this can clearly influence precipitation during subsequent heat treatments. Before investigating such heat treatments, SAXS analyses were performed at $25^{\circ} \mathrm{C}$ to correlate the STEM data with the size distribution found by SAXS.

\subsubsection{Correlation between STEM and SAXS results}

The precipitates size distributions were estimated from SAXS data fitting with a Monte Carlo procedure similar to that of the McSAS algorithm [10,11]. It has been performed for both the deformed and undeformed alloys, and they are presented in Fig. 6. First, these curves show that both samples contain a population of precipitates with a size between 0.5 and $1.5 \mathrm{~nm}$, consistent with GP zones [9].
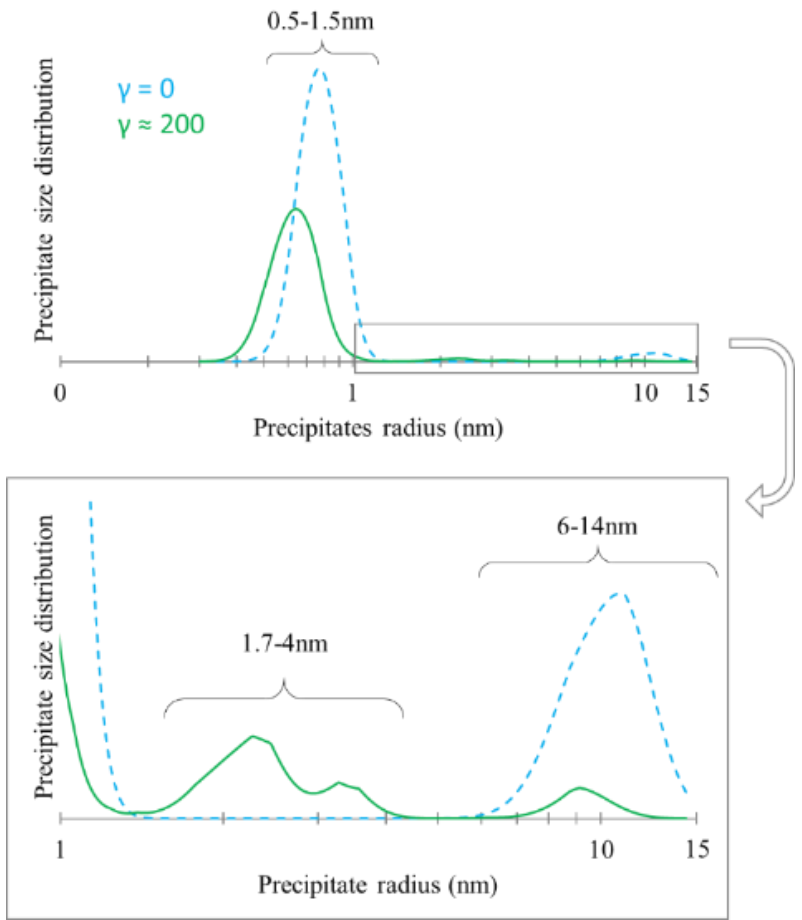

Fig. 6 : Precipitate size distribution estimated from SAXS data fitting for un-deformed (dashed line) and deformed (full line) $\mathrm{Al}-\mathrm{Zn}-\mathrm{Mg}-\mathrm{Cu}$ alloy.

However, the areas under the curves suggest that there is a higher volume fraction of these precipitates for the un-deformed sample. Besides, for this latter material, another population of precipitates is found with size between 6 and $14 \mathrm{~nm}$. This size corresponds to the intergranular precipitates observed by STEM. For the deformed sample, this population is also exhibited but with a much lower volume fraction as compared to un- 
deformed material. Nevertheless, a third population, with a size distribution between 1.7 and $4 \mathrm{~nm}$, is also exhibited but only in the deformed sample. This is consistent with the precipitates observed on defects by STEM.

These first results show that deformation by HPT leads to a nano-structuration of the structure with high level of defects like grain boundaries, sub-grain boundaries and dislocations. The deformation leads to precipitation of $\mathrm{Zn}, \mathrm{Mg}$ and $\mathrm{Cu}$ closely related to their segregation on the defects. A different precipitate size distribution as compared to un-deformed alloy is then achieved. This change could modify the alloy behavior during heat treatment. Indeed, it is well known that high density of defects usually leads to faster diffusion and decreased nucleation barrier. In previous works, precipitation sequence was changed or accelerated during heat treatment after severe plastic deformation $[9,16]$. The observed segregations could also have an influence during heat treatment.(ZH: I do not see description for Fig.7 before Fig.8.)

\subsection{Alloys behaviour during heating ramp}

DSC curves (Fig. 8) show clearly a different behaviour during annealing in continuous heating conditions between deformed and undeformed samples.

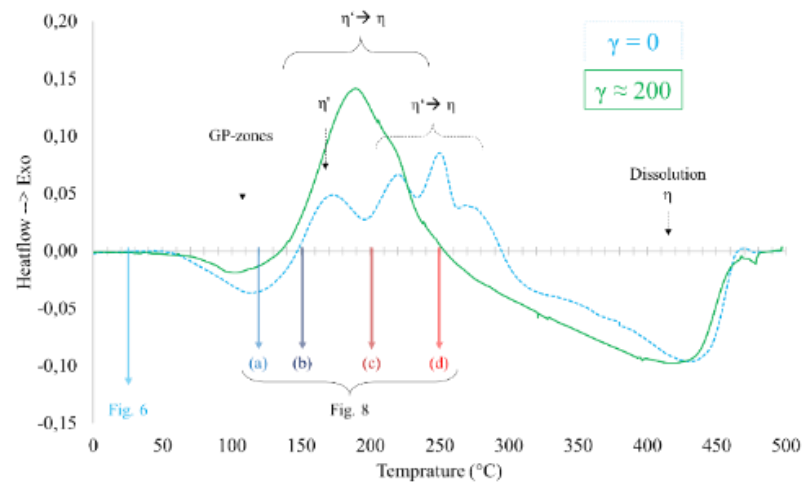

Fig. 8 : DSC curves of un-deformed (dashed line) and deformed (continue line) of $\mathrm{Al}-\mathrm{Zn}-\mathrm{Mg}-\mathrm{Cu}$ alloy during a temperature ramp of $20^{\circ} \mathrm{C} / \mathrm{min}$

Indeed, for the un-deformed sample, the precipitation sequence during $20^{\circ} \mathrm{C} / \mathrm{min}$ ramp is decomposed in several steps: Dissolution of GP-zones $\left(\sim 100^{\circ} \mathrm{C}\right)$, then, formation of $\eta$ ' precipitates $\left(\sim 170^{\circ} \mathrm{C}\right)$ and evolution of $\eta$ ' in stable $\eta$ precipitates $\left(\sim 200\right.$ to $\left.300^{\circ} \mathrm{C}\right)$. Finally, there is dissolution of precipitates between 320 and $450^{\circ} \mathrm{C}[15,17,18]$. In the deformed sample, the GPzones dissolution appears at lower temperature, the precipitation of $\eta$ ' also occurs at lower temperature $\left(\sim 80^{\circ} \mathrm{C}\right)$ and all the following transformations are gathered within the same exothermic peak (excepted for dissolution of precipitates). This shows a diminution of precipitation temperature followed by an acceleration of the precipitation kinetics. Indeed, the precipitation
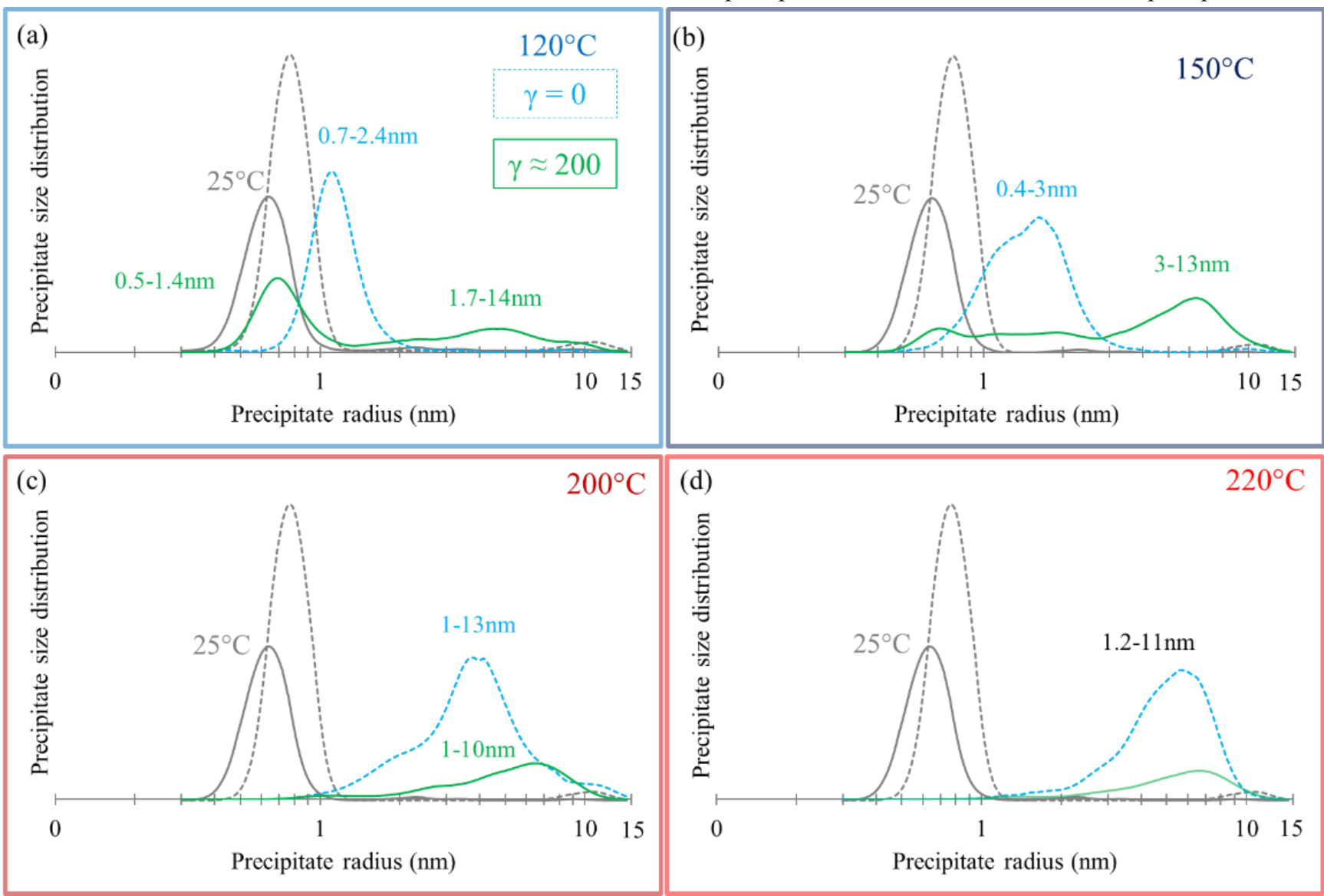

Fig. 7 : Precipitate size distribution estimated from fitting SAXS data for un-deformed (dashed line) and deformed (full line) Al-Zn-Mg$\mathrm{Cu}$ alloy at different temperatures during a ramp of $5^{\circ} \mathrm{C} / \mathrm{min}$ 
completion is around $300^{\circ} \mathrm{C}$ for the un-deformed sample and around $250^{\circ} \mathrm{C}$ for the deformed sample.

It can be noted that the area of the first endothermic peak, corresponding to the GP-zones dissolution, decreases with the deformation. It also seems to shift towards lower temperatures (from $120^{\circ} \mathrm{C}$ to $100^{\circ} \mathrm{C}$ ). According to [15], this would indicate the presence of smaller GP zones before annealing. Furthermore, the decrease in the peak area indicates a decrease in the GPzone volume fraction present in the samples deformed by HPT. Thus, the deformation induces a decrease in the size but also in the volume fraction of GP-zones. The segregations observed after deformation (Fig. 5) could reduce the quantity of elements available for homogeneous precipitation and may contribute to this difference. These results are in agreement with the SAXS curves at $25^{\circ} \mathrm{C}$ (Fig. 6) which show a lower volume fraction of GP-zones for the deformed sample with a smaller average size.

Then, different temperatures were chosen, and are indicated in Fig. 8 by arrows, to display SAXS precipitate distributions. It should be noted that the ramp is not exactly the same during DSC and SAXS experiments: $20^{\circ} \mathrm{C} / \mathrm{min}$ and $5^{\circ} \mathrm{C} / \mathrm{min}$ respectively.

Precipitate size distribution at $120^{\circ} \mathrm{C}$ (Fig. 7(a)) for the un-deformed sample shows a monomodal distribution with precipitate size between 0.7 and $2.4 \mathrm{~nm}$. So there is an increase of precipitate size and a decrease in volume fraction as compared to the distribution at $25^{\circ} \mathrm{C}$ (grey curve).

For the deformed sample, there is also a decrease in volume fraction and in the average size of this smaller population of precipitates. But the growth rate is lower and the decrease in volume fraction is more important ( $\sim 50 \%$ compared to $\sim 35 \%$ ) than for the un-deformed sample. Moreover, the volume fraction of bigger precipitates population $(2-14 \mathrm{~nm})$ increases.

At $150^{\circ} \mathrm{C}$ (Fig. $\left.7(\mathbf{b})\right)$, the area under the curve of the monomodal distribution for the un-deformed sample is $40 \%$ lower as compared to $120^{\circ} \mathrm{C}$. This shows an increase in volume fraction. A small increase in average size $(\sim 1.5$ $\mathrm{nm}$ to $\sim 2 \mathrm{~nm}$ ) is also observed. For the deformed sample, the behavior is completely different. Indeed, the volume fraction of smaller population continues to decrease and that of the bigger precipitates continues to increase.

At $200^{\circ} \mathrm{C}$ (Fig. $7(\mathbf{c})$ ), the volume fraction and the average precipitate size continue to increase for the precipitates of un-deformed sample. For the deformed sample, the small population of precipitates totally disappears. The average size of the larger precipitates population continues to increase but the volume fraction is now decreasing.

Finally, at $220^{\circ} \mathrm{C}$, the precipitate population of undeformed sample simply grows (increases in size but not in volume fraction). Contrarily to the precipitates population of the deformed sample which don't grow and exhibits a decrease in volume fraction.

These results show that in the undeformed sample, a progressive growth of precipitates occurs during the temperature ramp with first a decrease in volume fraction and then a kind of stabilization. For the deformed sample, there is a rapid loss of the small precipitates balanced by the formation of precipitates with a wide size distribution which rapidly decreases in volume fraction certainly because of the bigger precipitate population $(>15 \mathrm{~nm})$. The rapid precipitation kinetics and the wide range of size precipitates is in agreement with DSC curves, and also with the lower precipitation temperature.

\subsection{Alloys behaviour during isothermal treatment at $100^{\circ} \mathrm{C}$.}

Isothermal heat treatment was carried out on both samples and the microstructure evolution was followed both by SAXS and STEM.

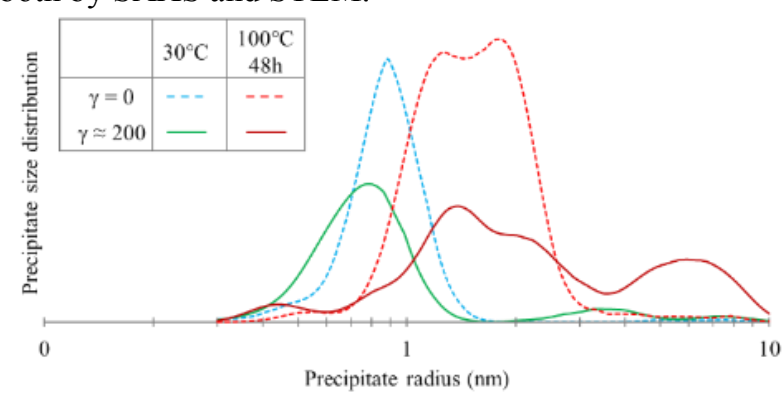

Fig. 9 : Precipitate size distribution estimated from fitting SAXS data for un-deformed and deformed sample, before and after thermal treatment at $100^{\circ} \mathrm{C}$ during $48 \mathrm{~h}$

Precipitates size distributions (Fig. 9) show a progressive growth of precipitates after $48 \mathrm{~h}$ at $100^{\circ} \mathrm{C}$ for the un-deformed sample. For the deformed sample, there are less GP-zones before the thermal treatment, (as discussed in previous section), and there is a simultaneous growth of these GP-zones and some precipitates which can be identified as $\eta$ ' or $\eta$. A large increase in volume fraction is also observed for these precipitates contrarily to the GP-zones volume fraction which is stable during this treatment.

The STEM images for un-deformed sample (Fig. 10 (a, b, c)) after this annealing treatment show homogeneous precipitation with precipitates size in a range of $0.5-3 \mathrm{~nm}$ and some heterogeneous precipitation (size $4-10 \mathrm{~nm}$ ).

For the deformed sample, dark field images (Fig. 10 (d)) show that the grain size is still below the micron size. HAADF images (Fig. 10 (e, f)) show two populations of precipitates, one on the defects with a size between 3 and $15 \mathrm{~nm}$, and one inside grains with a size between 0.7 and $3 \mathrm{~nm}$.

These observations are in good agreement with the SAXS measurements that revealed one population of precipitates for the un-deformed sample with a size between 0.4 and $1.5 \mathrm{~nm}(0.5-3 \mathrm{~nm}$ for STEM measurements) and two populations for deformed sample: $0.3-3 \mathrm{~nm}$ for smallest $(0.7-3 \mathrm{~nm}$ in STEM) and 3-10 nm $(3-15 \mathrm{~nm}$ in STEM). The population of heterogeneous precipitates observed in STEM for the un-deformed sample was not seen in SAXS certainly because of its very low volume fraction. 

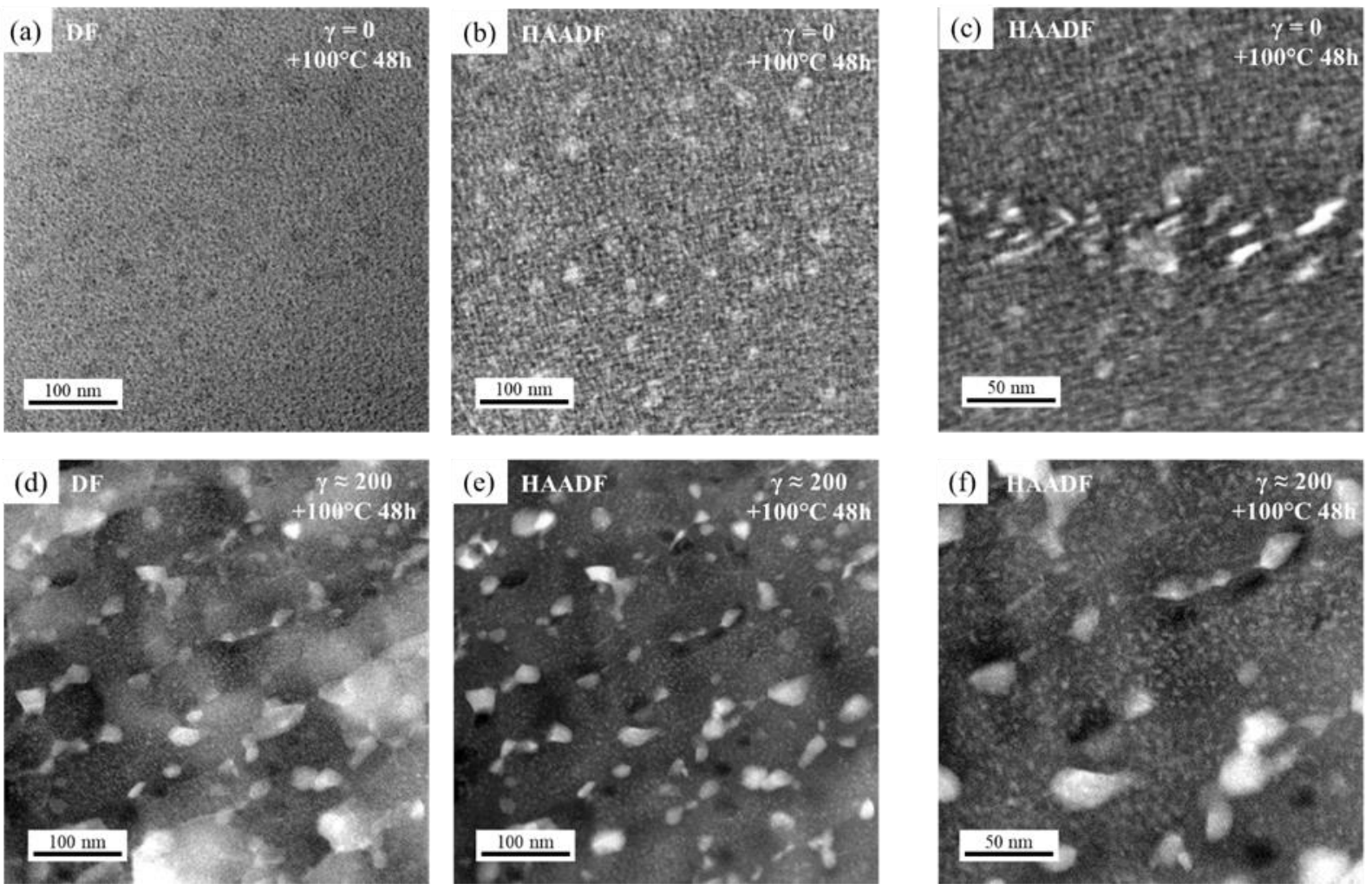

Fig. 10 : Dark field (a,d) and HAADF (b, c, e, f) images of un-deformed sample (a,b,c) and HPT deformed sample (d, e, f) of an Al-Zn-Mg-Cu alloy heat treated by $100^{\circ} \mathrm{C}$ during $48 \mathrm{~h}$

\section{Discussion}

First, this study shows that deformation by HPT does not influence the phases present in the alloy, meaning that there is no deformation induced phase transformation or total dissolution of another. However, many microstructural changes are caused by this severe plastic deformation. Observations by SEM show a fragmentation of $\mathrm{Al}_{7} \mathrm{Cu}_{2} \mathrm{Fe}$ intermetallic particles, but it is rather, limited since fragment sizes are still in the micrometer range.

Deformation-induced segregations on defects was observed after HPT, mostly on grain and sub-grain boundaries and probably along some dislocations. It has been proposed that this kind of segregation could be formed by several mechanisms. Dislocations can bring some solute to grain or sub-grain boundaries when annihilating. Segregations can also be formed by solute drag during the migration of a grain boundary [19]. Vacancies are created constantly during deformation and thus they may give rise as well to non-equilibrium segregations. Indeed, vacancies annihilate at grain boundaries which are defect sinks, a flow of vacancies towards the grain boundaries is then established during the deformation. If solute-vacancies complexes form, then vacancies bring solutes to boundaries creating segregation [20]. In the present case, STEM-EDS revealed such Zn, $\mathrm{Mg}, \mathrm{Cu}$ segregations.

STEM images show also some precipitation of $\mathrm{Zn}$, $\mathrm{Mg}, \mathrm{Cu}$ localized on defects. It can be the consequence of solute/defects interaction which increase the solute diffusion combined with high density of crystalline defects which decrease the nucleation barrier.
The distribution of solute atoms is therefore largely influenced by severe plastic deformation, and this can also have an influence on the following heat treatment or the thermal stability of the alloy as observed in this study.

Correlation between SAXS, DSC and STEM measurements allowed to follow the precipitation mechanisms in this deformed structure and to compare with the undeformed material subjected to the same annealing treatments. DSC shows a precipitation that starts at lower temperature than in the un-deformed alloy $\left(100^{\circ} \mathrm{C}\right.$ against $\left.120^{\circ} \mathrm{C}\right)$. It also shows that the stages of precipitation are not anymore sequential but become simultaneous, leading to a faster precipitation kinetics. SAXS results confirm this by evidencing a bimodal precipitates distribution compared to the monomodal one for the un-deformed sample and also by a larger size of precipitates and a faster decrease in volume fraction of precipitates smaller than $15 \mathrm{~nm}$.

The isothermal treatment made at $100{ }^{\circ} \mathrm{C}$ during 48 $\mathrm{h}$ by in-situ SAXS allows to further evidence this accelerated precipitation kinetics. In order to understand why two populations of precipitates are present in the deformed sample, observations with STEM were necessary. They show that the population of large precipitates is mostly localized on grain boundaries after annealing and the population of smaller particles is inside the grain. Thus, deformation leads to higher density of inter-granular precipitation compared to un-deformed alloy. Intra-granular precipitation still occurs in the deformed material but in a limited way (lower volume fraction of small precipitates observed by SAXS and STEM analyses). This balance can result from the high density of grain boundaries which generate high density of bigger precipitates, reducing the amount of solute for 
the intra-granular precipitation. Furthermore, the smaller size of intra-granular precipitates in the deformed sample (shown by SAXS and STEM) can also be a consequence of this lack of available solute.

\section{Conclusions}

This study allowed to understand first the influence of deformation on solute distribution in solid solution and more generally on the microstructure of an $\mathrm{Al}-\mathrm{Zn}-\mathrm{Mg}-\mathrm{Cu}$ alloy. But also the influence of this deformation on precipitation mechanisms by following the precipitate evolution using different observation methods. By DSC, and more specifically to followed precipitates size distribution by SAXS and the spatial arrangement of these precipitates thanks to STEM.

\section{Acknowledgements}

Both the Agence Nationale de la Recherche and the joint CNRS-JSPS 2017 summer program for the support to the trans-national collaboration are gratefully acknowledged for financial support (PRASA projectANR-15-CE08-0029). This work was also supported in part by Grant-in-Aid for Scientific Research (S) from the MEXT, Japan (No. 26220909). HPT was carried out in the International Research Center on Giant Straining for Advanced Materials (IRC-GSAM) at Kyushu University.

Thomas Dorin at Deakin university is thanked for casting the alloy.

\section{References}

[1] J.C. Williams, E.A. Starke Jr., Acta Materialia 51 (2003) 5775-5799.

[2] O. Andreau, J. Gubicza, N. Xian Zhang, Y. Huang, P. Jenei, T.G. Langdon, Materials Science and Engineering: A 615 (2014) 231-239.

[3] C. Xu, M. Furukawa, Z. Horita, T.G. Langdon, Acta Materialia 51 (2003) 6139-6149.

[4] Y. Estrin, A. Vinogradov, Acta Materialia 61 (2013) 782-817.

[5] D.C. Patil, K. Venkateswarlu, S.A. Kori, G. Das, M. Das, S.N. Alhajeri, T.G. Langdon, IOP Conf. Ser.: Mater. Sci. Eng. 63 (2014) 012085.

[6] S.-S. Wang, J.-T. Jiang, G.-H. Fan, A.M. Panindre, G.S. Frankel, L. Zhen, Acta Materialia 131 (2017) 233-245.

[7] A. Deschamps, G. Fribourg, Y. Bréchet, J.L. Chemin, C.R. Hutchinson, Acta Materialia 60 (2012) 1905-1916.

[8] K. Edalati, Z. Horita, Materials Science and Engineering: A 652 (2016) 325-352.

[9] A. Deschamps, F. De Geuser, Z. Horita, S. Lee, G. Renou, Acta Materialia 66 (2014) 105-117.

[10] I. Bressler, B.R. Pauw, A.F. Thünemann, J Appl Cryst 48 (2015) 962-969.

[11] B.R. Pauw, J.S. Pedersen, S. Tardif, M. Takata, B.B. Iversen, J Appl Cryst 46 (2013) 365-371.
[12] H. Queudet, S. Lemonnier, E. Barraud, J. Guyon, J. Ghanbaja, N. Allain, E. Gaffet, Materials Science and Engineering: A 685 (2017) 227-234.

[13] G. Sha, A. Cerezo, Acta Materialia 52 (2004) 4503-4516.

[14] H. Zhao, B. Gault, D. Ponge, D. Raabe, F. De Geuser, Scripta Materialia 154 (2018) 106-110.

[15] S. Liu, C. Li, S. Han, Y. Deng, X. Zhang, Journal of Alloys and Compounds 625 (2015) 34-43.

[16] M. Murayama, Z. Horita, K. Hono, Acta Materialia 49 (2001) 21-29.

[17] Y.H. Zhao, X.Z. Liao, Z. Jin, R.Z. Valiev, Y.T. Zhu, Acta Materialia 52 (2004) 4589-4599.

[18] J. Gubicza, I. Schiller, N.Q. Chinh, J. Illy, Z. Horita, T.G. Langdon, Materials Science and Engineering: A 460-461 (2007) 77-85.

[19] L. Priester, Les Joints de Grains: De La Théorie à l'ingénierie, L'Editeur: EDP Sciences, 2006.

[20] X. Sauvage, N. Enikeev, R. Valiev, Y. Nasedkina, M. Murashkin, Acta Materialia 72 (2014) 125-136. 